\title{
EDITORIAL: OUR CHOIR OF WORK-BASED RESEARCH
}

\section{Martin Andrew and Jan Hendrik Roodt}

Welcome to the second edition of Scope - Work-based Learning, with its broad theme of multiplicity of voices and its central musical metaphors of the chorus and the orchestra. In such contexts, voices work in complex ways beyond mere harmony singing from one hymn book. Voices can sing in four-part harmony or counterpoint, articulate in different techniques, generate sound effects, and engage in word painting. Choral voices can also merge, blur, and overlap in much that same way that voices in drama create a real-world of human chatter. Within the choral artefact, there can also be soloists. As editors, we have curated, or even orchestrated, a collection of various articles in the range of professional practice where voices are celebrated and given expression.

Scope - Work-based Learning 2 presents for you a veritable euphony/cacophony of the voices of members of communities of practice aligned to and with Otago Polytechnic's College of Work-based Learning and Capable NZ. Even the single-authored pieces, such as Martin Andrew's commissioned article, give voice to voices from the worlds of scholarship and practice, and reflect and sometimes refract the voices of the author's lived experiences and, by extension, the voices of those who are fellow-travellers on his own journey. Scope Work-based Learning 2, then, celebrates the multivocal nature of professional practice research, and recognises that such research cannot by its very nature happen in a vacuum, but is situated in a world of activity, one of workplaces, a world of pragmatic practitioners.

The musical metaphor reminds us that during 2021, Aotearoa New Zealand was one of few countries where orchestras or choirs were able to interact with audiences in physical and architectural spaces. Similarly, other groups that regularly meet to debate in such contexts as conferences, colloquia, symposia or summits, experienced grateful moments of 'actual' togetherness before migration to the 'virtual' spaces, where voices and the communications they convey presented different challenges and offered alternative dynamics. The ways in which COVID-19 has changed or impacted on the voices of professional practice research is an underlying theme of many articles. For Bonnie Robinson, the concatenation of the voices of the plover and the family feline offers a catalyst for an exploration of values-driven decision-making in leadership. We count among our voices not only the human, but also the calls of the whenua, the sounds of the world around us.

An observant reader may have groaned through several puns in the above paragraph, but the playfulness of voices in professional practice is also represented in items in this volume. There are epistolary collaborative duets between Claire Goode and Martin Andrew, and Alexa Forbes and Steve Henry, and even wider vocal ensembles in the study by Sandy Geyer and Henk Roodt. The latter ask the leading question, "How can we better prepare our future entrepreneurial/enterprise leaders earlier in their education?" and use multivocal methods to generate a response. Such studies draw on research methodologies that have come to the fore in times of pandemic, methodologies that can join voices across geographical and time zone barriers. One such methodology, community autoethnography, has proven to be a relationship-making activity among researchers who participate in, co-negotiate and co-construct each other's existence. Community autoethnography can be a disciplinary, transdisciplinary or multi-disciplinary approach and it helps its participants create a 'safer' environment for gaining in-depth and intimate understandings of any topic investigated.

The voices sing apart but together, aligned by the methodical processes of research and writing. Lesley Brook's multiplicity comes from investigating flux in her practice and emerging professional identity as an educational 
manager; it contributes to our understanding of the multiplicity of this role and, by extension, to how we view professional identities within vocational education. Mandy Pentecost creates a participant-voiced poem as a method of exploring professional identities - this time, those of the social worker with her dual, or more than dual, focus. The eloquent articulateness of participants underscores her vivid portrait of the profession in a work that "makes the shaping hand of the researcher apparent." Kathryn Wright contributes a slice of practice drawing on her multiple selves: "I am creative. I am patient. I teach. I am a writer. I am a counsellor. Some days, all of these things collide." Robert Nelson creates a rhyming poem, an ode to the multiple identities of his career, which engages the reader in rhetorical dialogue as its means of praxis. It is through such acts of collaboration that the kinds of changes both Nelson, Robinson, and Geyer and Roodt believe that agentive change is possible in the domain of leadership. There is an intimacy about this collection of studies, the kind of intimacy engendered by being impacted by the same phenomenon, in this case, COVID-19, the elephant in every room.

In some studies, the participatory nature of the methodologies for stakeholder engagement and research partnerships (Rodriguez and Cherrington, Macgregor et al.) evidence the multiplicity of voices involved in the generation of the study. The nature of the constructive critical conversation, as a method for supporting communication in leadership, education and coaching contexts, powers Marcia Johnson's choric, multi-voiced contribution, as she consults participants from multiple walks of voice as a necessary pivot of the COVID-19 era. The same is true of Glenys Ker and Martin Andrew's tribute to Capable NZ stalwart, Malcolm Macpherson, who is certainly more than the sum of what multiple voices say about him, but the voice-centred method indicates how identities are co-constructed discursively in professional practice.

The research in this volume is participatory, and it documents authors' interactions with their professional practice communities. We include articles of community-based ethnography, which has the key feature of being academically rigorous, socially responsive and multivocal. These are collaborative, often insider accounts, as in the studies led by Vicki Murray and Kevin Hollingsworth and their colleagues/whānau, where we hear the authentic songs and reflections of members of whānau, iwi, hapu. We hear Ka tiritiria: Our voices, and we encounter ways of unveiling research that are mana-enhancing, authentic and involving, in relation to two important topics: drug addiction and suicide prevention. The kete harakeke becomes symbolic of the collective artefacts of the community of practice in Murray's piece; it contains the power of group storytelling. Such studies involve a community-building or team-building activity as an approach to the production of professional practice knowledge and enact the principle that our work is stronger when we stand, and join, together. There is power here, and most importantly, there is hope.

Martin Andrew operates as a creative mentor in postgraduate programmes, including Master and Doctorate degrees in Professional Practice. Prior to his four to five years supporting the College of Work-based Learning in Otago, New Zealand, he had sojourned away from his hometown of Otepoti/Dunedin with two honorary posts at Melbourne universities in Creative Industries and Trans-national Education (TNE). His work and research have become increasingly focussed on doctorate education and supporting learners to reach their own personal best through critically reflective practice and writing. A transdisciplinarian, he emphasises that his past disciplines have included Education, Drama, Linguistics and Writing, Creative and otherwise. He holds honorary positions in Australia, Vietnam and Indonesia.

(D) https://orcid.org/0000-0002-0108-5195

Jan Hendrik Roodt is a transdisciplinary systems design engineer with business interests in New Zealand and Finland. He acts as postgraduate supervisor and assessor of masters and doctoral students in professional practice and applied innovation at the Otago Polytechnic and Waikato Institute of Technology in New Zealand. Based in Dunedin, he is a member of the Institute of Electrical and Electronics Engineers (Systems Council), the International Council on Systems Engineering, and Information Technology Professionals New Zealand.

(D) https://orcid.org/0000-0001-5250-8066 